\title{
Interruption of vector transmission by native vectors and "the art of the possible"
}

\author{
Roberto Salvatella ${ }^{1,2}{ }^{+}$, Pilar Irabedra ${ }^{1,2}$, Luis G Castellanos ${ }^{1}$ \\ ${ }^{1}$ Communicable Diseases and Health Analysis Department, Neglected, Tropical and Vector Borne Diseases Unit, Washington DC, USA \\ ${ }^{2}$ Regional Program for Prevention and Control of Chagas Disease, Montevideo, Uruguay
}

In a recent article in the Reader's Opinion, advantages and disadvantages of the certification processes of interrupted Chagas disease transmission (American trypanosomiasis) by native vector were discussed. Such concept, accepted by those authors for the case of endemic situations with introduced vectors, has been built on a long and laborious process by endemic countries and Subregional Initiatives for Prevention, Control and Treatment of Chagas, with Technical Secretariat of the Pan American Health Organization/World Health Organization, to create a horizon target and goal to concentrate priorities and resource allocation and actions. With varying degrees of sucess, which are not replaceable for a certificate of good practice, has allowed during 23 years to safeguard the effective control of transmission of Trypanosoma cruzi not to hundreds of thousands, but millions of people at risk conditions, truly "the art of the possible."

Key words: Chagas disease - vector control - interruption of transmission - certification - human infection - prevention

In the Reader's Opinion section of the magazine Memórias do Instituto Oswaldo Cruz, published in Rio de Janeiro in April 2013 (108: 251-254), there is an article written by Fernando Abad-Franch et al., where the advantages and disadvantages of the certification processes for the interruption of the transmission of Chagas disease (American trypanosomiasis) by native vectors are discussed. With regard to this, the authors of this article would like to enrich the analysis through the contributions that will follow.

Between 1991-1992 the Southern Cone Initiative (INCOSUR) was implemented to eliminate Triatoma infestans and interrupt the transmission via transfusions of American trypanosomiasis (INCOSUR/Chagas). This brought upon the Pan American Health Organization/Word Health Organization (PAHO/WHO) the role of Technical Secretariat, which added to their responsibilities the duty to offer support and coordination, in an international South to South cooperation scheme among countries, which originally implemented the following objectives (INCOSUR 1991): (i) elimination of T. infestans from all households and their surroundings in endemic areas, as well as areas considered "probably endemic", (ii) reduction and elimination of domestic infestations of other triatomine species present in the same zones occupied by $T$. infestans and (iii) reduction and

doi: $10.1590 / 0074-0276140338$

+ Corresponding author: salvater@uru.ops-oms.org

Received 26 June 2013

Accepted 26 September 2013 elimination of transmission via blood transfusions by improving blood bank networks and strengthening the selection process of efficient donors.

These goals, theoretically feasible to be achieved in the medium and long term, assuming the existence of resources which were never available in quality or quantity for INCOSUR/Chagas or any other of the Subregional Initiatiaves (Initiative of the Countries of Central America for Control of Vector-Borne and Transfusional Transmission and Medical Care for Chagas Disease-1997; Andean Initiative for Chagas Disease Control-1998) (OPS 1998, 2004), evolved into a target image that constituted a genuinely "virtual horizon" of potential expectations.

Between 1992-1999 (WHO 1998, 1999), the work objectives for the control of the disease were reconsidered by the countries, based on what at that moment they considered documented significant progress in Chagas control. Fundamentally these advances were made through vector control and the universal screening of blood donors as seen by achievements demonstrated mainly in Uruguay, Chile and Brazil.

It was through these developments that the concept of "interruption of the vector transmission of Trypanosoma cruzi" (OPS 2002, 2010), was first considered based on three concepts that are applied in a determined geographical context: (i) prevalence of the trypanosome infection in pre-school and school age children, intended to reflect the effective activity or inactivity of recent transmission, using values less than $2 \%$ in children between zero-five years of age as a base indicator; (ii) absence of clinical (or subclinical) evidence of acute Chagas cases, notified to the national health system of each country, assuming that the presence of one reported case in the last three 
years equals a diagnosis of an active transmission of $T$. cruzi in the area. It is important to note that the diagnosis could occur in conditions of low sensitivity following the surveillance capacity of each country; (iii) indicators of domestic infestation (disaggregated in intra and peridomicile) by the main triatomine specie, as a vector implicated in active transmission of disease at the geographic area under consideration; given that its low quantification would prove the low possibilities of transmission. This indicator would be used alongside other entomological indicators that provide further information specific to each case being evaluated. The following would be used as base indicators: infestation index equal to or less than $1 \%$ disaggregated into intradomicile infestation index and peridomicile infestation index. In the case of autochthonous vectors the peridomicile infestation index can be up to $5 \%$.

The concept of "interruption of the vector transmission of T. cruzi" according to Abad-Franch et al. (2013), has been useful and effective for the control of vectors introduced (not native) in: Uruguay (1997), Chile (1999), Brazil (2006), Oriental Region of Paraguay (2008), several provinces or department of Argentina (2001, 2004, 2011, 2012), two departments of Peru (Tacna 2009, Moquegua 2010), two states in the south of Mexico (Chiapas and Oaxaca 2009), Guatemala (2008), Honduras (2010), Nicaragua (2010), El Salvador (2010) and Costa Rica (2011). The same authors, however, consider that the utilization of the same concept would not have similar outcome in areas where the transmission depends on species that are native, using as examples the department of La Paz (Bolivia), "some localities in Chaco, Argentina" and non-Amazonian endemic areas of Brazil.

It is important to emphasise that all the certification processes follow a protocol clearly described (OPS 2002, 2010) that contemplate, among others, the participation of international and national experts of the country and the region where the interruption verification work is carried out. Important criteria also used are based on information provided by the country, revision of alternative reports and studies available by other bibliographical sources and information from the national epidemiological system of the implicated country.

In the case of the examples cited previously (La Paz, Chaco from Argentine and non-Amazonian areas of Brazil), the following must be considered: the department of La Paz, Bolivia, received its certification in 2011 based primarily on a random sample of 5,301 children between zero-five years of age, taken from 330 communities of 21 endemic municipalities of La Paz, where only $45(0.8 \%)$ pre-school children were positive and whose mothers were also positive. All of this was demonstrated through serologic studies using rapid tests, ELISA and reconfirming positive cases and randomly selected negatives samples. These results came from the same area where in 1990 the prevalence was $15.6 \%$ for the same study groups. In 2011, the index value for domestic infestation by $T$. infestans in La Paz was 1.3\% with a clear predominance of peridomicile (SEDES/La Paz 2010, MSDB 2011). Within the four years previous to 2011 there are no reports of acute Chagas cases diagnosed in the department of La Paz (OPS 2011).
Described as "some localities in Chaco, Argentina," the departments of Aguirre, Mitre, Belgrano, Rivadavia, Ojos de Agua and Quebrachos in the south of the province of Santiago del Estero were evaluated between the years 2012-2013. A significant drop of intradomestic infestation by $T$. infestans was confirmed, with values between $0.26-1 \%$. This reduction was assumed to be the result of vector control and the environmental transformations of development (MSDSSE 2012, 2013). These results came from the use of large percentages of the total population of children in each community, represented by pre-school age population, more specifically, zero-five years of age [194 children from Aguirre (24\% of the total $0-5$ age group population), 108 children from Mitre (47\%), 83 children from Belgrano (18\%), 125 children from Rivadavia (23\%), 752 children from Ojos de Agua (47\%) and 670 children from Quebrachos (50\%)]. The prevalence value was of $0 \%$, using serology based on techniques from Serokit and ELISA. The previous outcome is in contrast to the results found in studies performed in the same communities and population groups, where between 1994-1996 the prevalence in the group of children between zero-five years was of 5.8\% in Aguirre, 2.4\% in Mitre, 6\% in Ojo de Agua and 3.4\% in Quebrachos (MSDSSE 2012, 2013). Additionally, between 2012-2013, other studies were performed using subject groups from school age children (ages 5-15) via questionnaires that included from $80-99 \%$ of the total children population of that range [1,133 children from Aguirre (98\%), 258 children from Mitre (99\%), 1,487 children from Belgrano (98\%), 720 children from Rivadavia (98\%), 2,622 children from Ojo de Agua (80\%) and 2,186 children from Quebrachos (86\%)], resulting in detected prevalence values between $0.2-1 \%$. These departments of Santiago del Estero have no recorded diagnosis of acute cases since 2000 (MSN/SPPS 2011).

In the case of the endemic extra-Amazonian states of Brazil, where the infestation by T. infestans (Silveira et al. 1984) never existed, as shown in the national seroepidemiologic survey of 2001-2008 (Luquetti et al. 2011), it was demonstrated that the autochthonous vectors did not have any major impact on transmission within the domestic environment (based on a representative sample of children from $0-5$ years of age): Ceará ( 2 positive cases in 9,797 samples), Rio Grande do Norte (1 case in 1,750), Alagoas (2 in 3,723), Sergipe (0 in 2,552) and Espírito Santo (0 in 1,885). This demostrates that in these territories, as well as in all extra-Amazonian areas, "there was a significant reduction in the rate of transmission of human Chagas disease in the country without any current recording of a continuous and/or sustained domestic transmission. The national seroprevalence survey (20012008) evidenced this situation for the whole endemic territory (OPAS/OMS 2012). No acute Chagas cases have been registered in these states since 2008 (MS 2012).

According to general literature, which are consistent with the technical guides utilised by $\mathrm{PAHO} / \mathrm{WHO}$, the term "elimination" is essentially a state of control (many times ideal) that requires permanent interventions in a community to be able to sustain such achievement. This 
is in contrast to eradication, which does not require further interventions after reaching the goal (Dowdle 1998, 1999, Cochi \& Dowdle 2011, Hopkins 2013).

Without any doubt the "interruption of the vector transmission of $T$. cruzi" by autochthonous (native) triatomines, is a goal adopted for control purposes. This is used because of its practicality and concrete methods of measuring the achievement and progress of work through time and because of the dynamic evolution of the factors that intervene in the transmission of this disease. This goal of elimination depends on an installed, sustainable and feasible surveillance that adapts to the necessities of each epidemiological scenario for its periodic registration. Such surveillance system should guide the programs of control of the disease in the decision-making process over which actions need to be taken next, including the necessary adjustments that need to be made so that such actions are effective. All this keeping in mind possible distracting elements such as, the adaptation or substitution of the transmission vectors, modifications in the population dynamics or, eventually, the resistance to insecticides. This does not ignore the fact that in a zoonosis with a natural sylvatic cycle, the occurrence of isolated cases, sporadic or accidental, of human Chagas, or the documented existence of likely scenarios to the recurring peri or intradomiciliary colonisation of some species of vectors, that until now have not demonstrated significant evidence of public health importance, should not be considered in the existing epidemiological surveillance routine.

Even in more important species such as T. infestans, situations exist, such as that in Chile, a country with a recognised status of "interruption of the vector transmission of T. cruzi" since 1999 (WHO 1999, Lorca et al. 2001), that do register the presence of this specie in wild habitats of Regions V, IV and Metropolitan (Bacigalupo et al. 2010).

$\mathrm{PAHO} / \mathrm{WHO}$ has been consistent with the countries of the Americas, promoting and supporting a technical cooperation that is effective an evidence-based. All this is done for the development of a strengthened surveillance (in quality, sensibility and coverage), strategically integrated to the national epidemiological surveillance and methodologically feasible. This includes the better use of diagnostic laboratory tests most ideal to each country and region. Because of this, such cooperation is fundamental in order to progress toward the prevention of new cases and the control of Chagas. Nevertheless, the final decision of the countries to confront the challenge and give priority to this health topic and regional pathology, must offer clear and feasible goals of public health impact, similar to those that invigorated throughout 23 years the existence of the Subregional Initiatives, making them successful.

It is probable that the general transformations of Public Health in the Region during the last three decades had influenced negatively the public health policy decisions made as well as the assignment of resources, recognising Chagas disease as a problem only at the bottom of priorities. This does not necessarily might be linked to the responsibility of the "punishment of success", that is, to greater control fewer resources. The Americas have been traditionally a leader in these processes of Public Health in other fields, such as immunopreventable diseases and neglected infectious diseases. More importantly, these countries have continue responding responsibly to the challenges of maintaining such reached goals.

There is still a lot to be done and a proposal of evaluation of "good practices" in the prevention, control of Chagas disease, as a complimentary evaluating mechanism of "process", is supported by PAHO/WHO. Such proposal could help improve the conceptual framework and fieldwork that must be perfected and democratised in the space of the Subregional Initiatives. Nonetheless, it is clear that such proposal does not constitute as an alternative to the impact evaluation of work developed by the countries that are struggling to reach the "interruption of the vector transmission;" which as of now it continues to be transitional and modifiable and yet, the best available option to measure the progress made in a Public Health scale ("the art of the possible").

\section{ACKNOWLEDGEMENTS}

PAHO would like to acknowledge all health workers of all times, whom day by day, add their silent and constructive effort on the field and home by home, under the most difficult geographical conditions and circumstances, to protect their communities from the vector transmission of Chagas disease.

\section{REFERENCES}

Abad-Franch F, Diotaiuti L, Gurgel-Gonçalves R, Gürtler RE 2013. Certifying the interruption of Chagas disease transmission by native vectors: cui bono? Mem Inst Oswaldo Cruz 108: 251-254.

Bacigalupo A, Torres-Pérez F, Segovia V, García A, Correa JP, Moreno L, Arroyo P, Cattan PE 2010. Sylvatic foci of the Chagas disease vector Triatoma infestans in Chile: description of a new focus and challenges for control programs. Mem Inst Oswaldo Cruz 105: 633-641.

Cochi SL, Dowdle WR 2011. Disease eradication in the 21st century: implications for global health. Strungmann forum report, Vol. 7, MA MIT Press, Cambridge, 311 pp.

Dowdle WR 1998. The principles of disease elimination and eradication. Bull World Health Organ 76 (Suppl. 2): S22-S25.

Dowdle WR 1999. The principles of disease elimination and eradication. MMWR 48 (Suppl. 1): S23-S27.

Hopkins D 2013. Disease eradication. N Engl J Med 368: 54-63.

INCOSUR - Iniciativa Intergubernamental de Salud de los Países del Cono Sur 1991. Resolución sobre Control de Enfermedades Zoonóticas (04-3-CS), PAHO, Brasilia, 85 pp.

Lorca M, García A, Bahamonde MI, Fritz A, Tassara R 2001. Certificación serológica de la interrupción de la transmisión vectorial de la enfermedad de Chagas en Chile. Rev Med Chil 129: 266-271.

Luquetti A, Passos AC, Silveira AC, Ferreira A, Macedo V, Prata A 2011. O inquérito nacional de prevalência de avaliação do controle da doença de Chagas no Brasil (2001-2008). Rev Soc Bras Med Trop 44 (Suppl. 2): S108-S121.

MS - Ministerio da Saúde 2012. Doença de Chagas. Aspectos epidemiológicos. Available from: portal.saude.gov.br/portal/saude/ profissional/visualizar_texto.cfm?idtxt=31454. 
MSDB - Ministerio de Salud y Deportes de Bolivia 2011. Informe situacional. Prevención, control e impacto hacia la certificación de la interrupción de la transmisión vectorial de Trypanosoma cruzi por Triatoma infestans en 23 municipios endémicos del departamento de La Paz, MSDB, La Paz, 23 pp.

MSDSSE - Ministerio de Salud y Desarrollo Social de Santiago del Estero 2012. Documento técnico. Interrupción de la transmisión vectorial de T. cruzi en los departamentos de Aguirre, Belgrano, Mitre y Rivadavia, MSDSSE, Santiago del Estero, 50 pp.

MSDSSE - Ministerio de Salud y Desarrollo Social de Santiago del Estero 2013. Documento técnico. Interrupción de la transmisión vectorial de T. cruzi en los departamentos de Ojo de Agua y Quebrachos, MSDSSE, Santiago del Estero, 76 pp.

MSN/SPPS - Ministerio de Salud de la Nación/Secretaría de Promoción y Programas Sanitarios 2011. Boletín Integrado de Vigilancia 93 SE 40, MSN, Buenos Aires, 69 pp.

OPAS/OMS - Organização Pan-Americana da Saúde/Organização Mundial da Saúde 2012. Oficina para discussão da proposta de "certificação da interrupção da transmissão da doença de Chagas por vetores secundários no Brasil", June 5-6 2012, OPAS/OMS, Brasilia, 3 pp.

OPS - Organización Panamericana de Salud 1998. Primera Reunión de la Comisión Intergubernamental de la Iniciativa de Centroamérica y Belice para la Interrupción de la Transmisión Vectorial de la Enfermedad de Chagas por Rhodnius prolixus, disminución de la infestación domiciliaria por Triatoma dimidiata y Eliminación de la Transmisión Transfusional del Trypanosoma cruzi, $\mathrm{OPS} / \mathrm{HCP} / \mathrm{HCT} / 145 / 99$, Guatemala, $18 \mathrm{pp}$.

OPS - Organización Panamericana de Salud 2002. Guía de Evaluación de los procesos de control de triatomineos y del control de la transmisión transfusional de T. cruzi, OPS/HCP/HCT/196.02, OPS, Washington, 8 pp.

OPS - Organización Panamericana de Salud 2004. Comisión Intergubernamental de la Iniciativa Andina de Control de la Transmisión Vectorial y Transfusional de la Enfermedad de Chagas, OPS/HCP/HCT/223/04, OPS, Lima, 35 pp.

OPS - Organización Panamericana de Salud 2010. Marco referencial de los procesos hacia la interrupción de la transmisión vectorial de T. cruzi. Guía de definiciones, OPS, Montevideo, 2 pp.

OPS - Organización Panamericana de Salud 2011. XVIIIa Reunión de la Comisión Intergubernamental de la Iniciativa Subregional Cono Sur de Eliminación de Triatoma infestans y la Interrupción de la Transmisión Transfusional de la Tripanosomiasis Americana, Cochabamba, Bolivia, 2011 Julio 27-29, Document HSD/CD/008-11, Organización Panamericana de la Salud, Montevideo, $69 \mathrm{pp}$.

SEDES/La Paz 2010. La enfermedad de Chagas "una tragedia silenciosa". Boletín Informativo Epidemiológico SEDES/La Paz 4: 1-6.

Silveira AC, Feitosa VR, Borges R 1984. Distribuição de triatomíneos domiciliados no período 1975/1983 no Brasil. Rev Bras Malariol D Trop 36: 15-312.

WHO - World Health Organization 1998. Chagas disease, interruption of transmission in Uruguay. Wkly Epidemiol Rec 2: 1-4.

WHO - World Health Organization 1999. Chagas disease, interruption of transmission in Chile. Wkly Epidemiol Rec 2: 9-11.

\section{REPLY}

On bugs and bias: improving

Chagas disease control assessment

We welcome the positive response by Salvatella et al. to our proposal of issuing "certificates of good practice" (CGPs) to vector control programs seeking to interrupt or, at least, reduce the transmission of Trypanosoma cruzi to humans (Abad-Franch et al. 2013). Public health scientists, program managers and international agency officials we all share the same fundamental mandate: to come up with what is best for people living at risk of being infected by T. cruzi. But to help improve disease prevention and control programs we need to reassess the adequacy and implications of past and current evaluation practices and, when necessary, openly debate over innovative strategies to find the best way forward.

Roots of the debate - Our opinion piece stemmed from a meeting held in Brasilia on June 2012 to discuss the possibility of certifying the interruption of T. cruzi transmission (CIT) by native, "secondary" vector species in Brazil. We sought to raise awareness about the dangers of making influential public health decisions based on achievements that are not properly documented and/or that may not be applicable under many common circumstances. In particular, we believe that formerly successful recipes against non-native vector populations (Triatoma infestans in Brazil or Rhodnius prolixus in Central America) are unlikely to work against native vectors in current scenarios dominated by low political priority, decentralisation of health systems and weaker vector control services.

Native vectors maintain widespread foci in natural habitats from which they regularly invade and sometimes colonise human dwellings. They play substantial roles in T. cruzi transmission to humans and we must incorporate this complexity into our strategies and policies. Importantly, all New World triatomine species, including the main "domestic" vectors (T. infestans, R. prolixus and Triatoma dimidiata), are native to some region in the Americas. Our letter called attention to these issues and suggested a general strategic framework for the current and future scenarios of vector-borne Chagas disease.

The elimination of non-native vector species relied on area-wide, blanket insecticide-spraying campaigns conducted by professional spray teams from verticallystructured control programs. This so-called "attack" phase worked well, although not everywhere, and CITs were overall justified for some regions in the past scenario of the 1990s. Progress from the vertical attack phase to a longitudinal surveillance phase was based on an assessment of impact at various levels (locality and state, province or department). Unfortunately, the surveillance phase was often discontinued after CITs were issued; this happened, for instance, in many Brazilian municipalities. The powerful notion of "interruption of transmission" made it hard to justify efforts and investment in vector and disease surveillance. The emergence and expansion of dengue, combined with decentralisation of health services, also distracted resources away from Chagas disease control throughout Latin America 


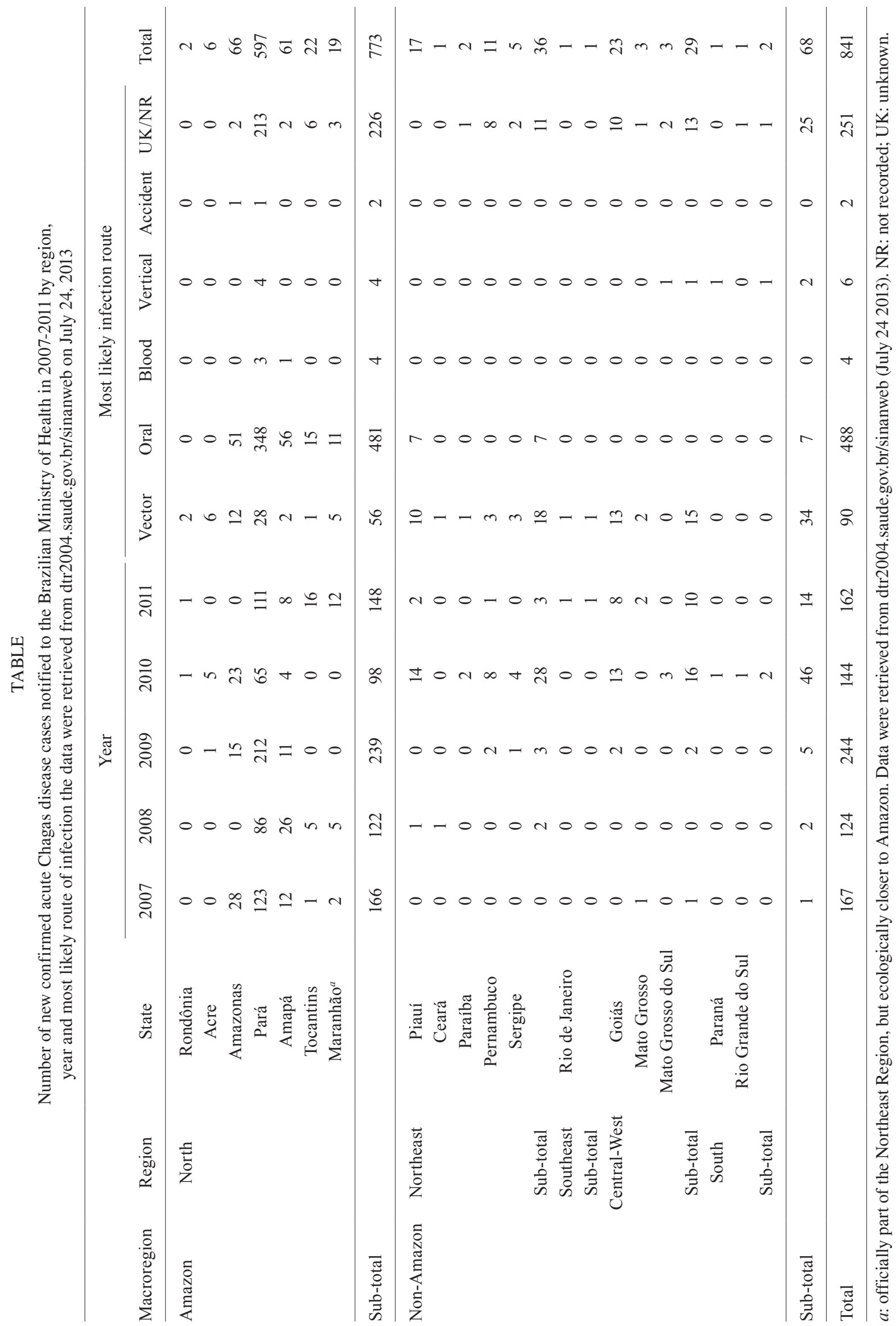


(Yadón et al. 2006). The Brazilian case clearly illustrates one major potential side effect of CIT-based policies: the deactivation of longitudinal surveillance systems is a very likely outcome.

Current scenarios of T. cruzi transmission and vector control [summarised in Table of Abad-Franch et al. (2013)] differ in several ways from those that prevailed in the 1990s. Although non-native vectors persist in several countries (e.g., residual T. infestans foci in Brazil), most transmission, whether endemic or in the form of outbreaks, is now driven by native vector populations. In addition, pyrethroid resistance has emerged as a new critical obstacle here and there. In spite of these difficulties, some vector control programs keep working well in certified areas, but the threats are many. What are the technical drawbacks of CITs? How can major apparent advances be consolidated and disease resurgence prevented in the current and future epidemiological scenarios?

Validity of the metrics used in Chagas disease control program assessment - Here we will argue that estimators of the key parameters used in the assessment of Chagas disease control status are all biased down. These estimators are really indices, not statistical estimates and both the magnitude of their bias and their precision remain uncertain. We have tried to reasonably approximate bias for the most important metrics.

Infestation - House infestation prevalence is always underestimated simply because standard timed manual searches for vectors suffer from large ascertainment bias. The probability of detecting at least one bug in a dwelling that is actually infested is typically well below $50 \%$ and decreases as insecticide-based control brings both infestation and bug density to the brink of detection thresholds (Abad-Franch \& Ferraz 2010, Abad-Franch et al. 2011, Rojas de Arias et al. 2012). Bug search efficiency depends on the skills of field staff, total search effort or the use of "flushing-out" chemicals; however, no bug-detection method works perfectly and true infestation values remain unobservable. Standard vector surveys provide biased infestation indices that reflect only vaguely programmatic targets such as "house infestation below 1\%". When observed house infestation is about $1 \%$ based on active point searches after insecticide spraying, it would be safer to assume that the true underlying prevalence is somewhere between 10-40\% (Rojas de Arias et al. 2012). This makes a big difference both for program management and for disease prevention purposes.

Since the CIT for T. infestans was issued, most Brazilian municipalities (currently in charge of vector control) stopped from devoting adequate or any resources to triatomine bug surveillance. Together with the incomplete decentralisation of health services (Yadón et al. 2006), this has severely weakened their capacity to collect reliable data on house infestation and react accordingly. Thus, the bias in infestation index values is most likely growing still worse across Brazil and in many other countries.

Infection prevalence - Despite the high sensitivity and specificity of serological methods in current use, infection prevalence estimates are not immune to bias. One key problem is that most impact assessment sur- veys are based on convenience samples or on designs that make implausible assumptions about the frequency and spatial distribution of infection in the target populations (Abad-Franch et al. 2010). There are inherent difficulties to getting representative samples in the remote and resource-poor rural areas where T. cruzi infection prevalence is higher; if these communities are undersampled, we should expect prevalence estimates to be biased down. More generally, simple designs (random, systematic or cluster-random sampling) are very likely to underestimate true prevalence when events are rare and clustered in space (Thompson 2004, Conroy et al. 2008). A reliable estimation of the prevalence of rareand-clustered events (of which T. cruzi infection is now a clear example) requires elaborate sampling designs and analytical approaches. Consequently and as we saw for infestation, the observed sample proportion (the infection index) is most likely a biased estimate of the true underlying prevalence of infection.

There are additional complications with serological surveys. For example, most of them use whole-blood samples collected on filter paper or diluted in glycerin; the quality of the sampling procedure, sample storage and sample processing can all affect the sensitivity of serological tests, yet this is rarely taken into consideration. Even under the best possible conditions, no available serological method is error-free - some false-positive and some false-negative results are to be expected. A systematic review of high-quality diagnostic tests for Chagas disease found an overall sensitivity of $90 \%$, with a $95 \%$ confidence interval of $89-91 \%$ (Afonso et al. 2012). This introduces further bias and further elaborations are necessary to cope with that bias (e.g., Walter \& Irwig 1988, Chao et al. 2001).

In ordinary practice, however, all these issues are simply ignored: the sample proportion of "positive" observations, usually from a convenience sample, is taken as if it were an unbiased estimate of the underlying prevalence, when it is not. Sampling and ascertainment bias are too pervasive and should be taken into account when evaluating disease and vector control programs.

Incidence - Acute Chagas disease is a compulsorynotification condition in Brazil and many other countries. A total of 841 new confirmed cases of acute Chagas disease were recorded from 2007-2011 in the publicly-available database of the Ministry of Health of Brazil (Table). For one of these cases to be recorded, the following chain of events is logically necessary: (i) the case has to be diagnosed, (ii) the diagnosis has to be confirmed in the laboratory, (iii) the confirmed case must be documented in a special form and effectively notified and (iv) the record has to be processed and entered into a database. Because acute $T$. cruzi infections are typically asymptomatic or oligo-symptomatic (Rassi et al. 2010), it is very likely that most acute cases go unnoticed; many do not reach the point-of-care facility and some patients are misdiagnosed. In addition, no perfect laboratory procedure (i.e., with $100 \%$ sensitivity) is available for diagnosis or confirmation and not all doctors effectively notify the cases they detect. What is, then, the probability of getting one reported acute case given one infection? 
A rough calculation based on our best-guess estimates of probabilities along the chain of events suggests that only about $15 \%$ of all vector-borne and $60-70 \%$ of all oral acute cases (which typically also involve native vectors) are reported. Thus, excluding blood-borne, vertical and accidental infections, about 750 new cases per year (most mediated by native vectors), would have to occur to generate the observed records presented in the Table. Congenital cases provide further insight into underreporting: according to PAHO (2006), 5,000 cases are expected to occur each year in Brazil. Therefore, approximately 25,000 congenital cases would have occurred during 2007-2011 - but only six were reported.

Case notification data contradict the view that transmission of $T$. cruzi to people by native or secondary vectors has been interrupted in Brazil. More importantly, it is clear that case notification data reveal only the tip of the iceberg - just as cross-sectional vector surveys reveal only the tip of another, related iceberg. This is barely surprising for anyone familiar with Chagas disease diagnosis and notification. We finally note that while some of the drawbacks of current surveillance systems are purely technical, some others will require policy changes. We firmly believe that CGP-based strategies can help stimulate such changes and improve control strategies.

A case study: La Paz - That observed infestation and infection prevalence have sharply declined in La Paz department, Bolivia, as a consequence of control actions is very good news. But, as discussed above, we must consider the uncertainty about the metrics used to certify interruption of transmission in La Paz.

First, while serological results appear impressive, they can only be assessed rigorously by knowing how exactly sampling and testing were performed at all scales (from department down to localities and individuals) and both in the more recent assessment and in the 1990 survey chosen for comparison. Importantly, the 1990 survey was based on a sample of only 35 subjects (PAHO 2011). Furthermore, 15 (35\%) of the mothers of T. cruzi-seroreactive children recently detected could not be tested serologically (PAHO 2011). The observation that a seropositive child has a seropositive mother might indicate vertical transmission, but does not exclude the possibility of infection through contact with vectors. As regards incidence, if no new Chagas disease case has been detected through the local surveillance system (PAHO 2011), then this system missed at least the 45 cases detected during recent serosurveys. Moreover, about 1,500 new congenital cases are believed to occur each year in Bolivia (PAHO 2006). The demographic share of this figure for the at-risk municipalities in $\mathrm{La}$ Paz may be about 30-35 new cases per year (or about 160 during 2007-2011) yet none was reported. A similar argument applies to southern Santiago del Estero in the dry Argentinean Chaco. Like in the Brazilian case, epidemiological silence has many possible meanings and has to be interpreted with caution.

La Paz infestation data are also impressive - but they come with caveats too. First, T. infestans populations (and, most importantly, wild populations) are not uniformly distributed among municipalities because of eco- logical heterogeneity. The overall prevalence of infestation is therefore unlikely to be a good estimate of local prevalence. Most municipalities (71\%) lie within ecoregions from which wild $T$. infestans populations may be absent (the Yungas and the humid Andean valleys), but there are six municipalities in the dry valleys where wild populations are widespread (Noireau et al. 2005, Buitrago et al. 2010). We would therefore expect low average infestation prevalence after insecticide spraying, but with higher values in dry-valley regions. This is precisely what the data show: median municipality-level infestation values were $2.2 \%$ in the dry valleys (range, $0.6-4.3 ; \mathrm{n}=6), 0.15 \%$ in the humid valleys $(0.0-2.2 ; \mathrm{n}=$ 8 ) and $0.6 \%$ in the Yungas $(0.0-1.0 ; n=7)$ (PAHO 2011). Despite the small sample size, differences between ecoregions are statistically significant (Kruskal-Wallis test, $\chi^{2}=7.32$, degrees of freedom $=2, p=0.026$ ). But if $1.3 \%$ of dwellings were found to be infested after insecticide spraying, then the true overall prevalence should be assumed to be about $25 \%$ - or somewhere between 10 $40 \%$, with higher values in dry-valley localities.

In summary, despite the program's achievements, which we obviously welcome, several major potential sources of uncertainty about La Paz data do not seem to have been properly addressed. If the evaluating experts had access to additional information, which convinced them that the data reported in PAHO (2011) accurately reflect reality, this would of course strengthen the case for interruption of T. cruzi transmission to humans at the department level. But even if that were the case, we seriously doubt that awarding a CIT would bring any mid or long-term benefit to people living at risk. The odds seem high that priority would decline as a consequence of certification; then, as happened in Brazil and parts of Argentina, funding, control-surveillance activities and expertise may all dwindle. This adverse scenario would take place in areas where wild T. infestans populations are common and substandard housing is pervasive; additionally, pyrethroid-resistant vector populations occur in nearby districts. In contrast, certifying good practice would likely help secure the resources needed for sustained control responses, retaining full operational capacity and expertise. The crucial issue in high-risk scenarios such as the dry valleys of La Paz is sustainability of disease and vector control-surveillance programs (Gürtler 2009). This also applies, in our opinion, to other Bolivian departments, the Gran Chaco, Brazil and indeed to most rural and periurban areas of the Americas where native vector populations are common and frequently invade and sometimes colonise human residences (Abad-Franch et al. 2013).

The way forward - The goal of assessing program performance is to improve program performance. Because program targets are "moving targets" (vector and parasite populations adapting to changing environments), performance is necessarily a dynamic concept and we therefore need dynamic assessment frameworks. Instantaneous or "snapshot" measures of impact are likely to quickly become outdated. For example, the results of the last Brazilian national serological survey, arguably the 
most carefully designed and conducted in the country (Ostermayer et al. 2011), seem of limited current validity: 69 new cases in the zero-four years age class were recorded by the (clearly imperfect) official notification system in 2007-2013 (Figure), whereas the serosurvey only detected 32 cases among 105,000 children aged zero-five years tested in 2001-2008. More generally, the bold conclusion drawn from the national serosurvey (that vector-borne Chagas disease is "virtually inexistent" in Brazil) (Ostermayer et al. 2011, Salvatella et al.) contrasts sharply with the Ministry of Health records in the Table and Figure. This suggests that serosurvey results may have important limitations, likely because of design issues - including the assumption that most transmission events are restricted to young children, which current evidence apparently contradicts (Figure). Thus, the results of similar serosurveys (in Brazil, La Paz or elsewhere) may be hardly informative and even potentially misleading if, for example, the age-specific force of infection has changed, as the Figure suggests. Since the CGPs we outlined in our previous opinion paper are conceptually dynamic, they would, by definition, match the needs of dynamic assessment better than any "snapshot" measure of impact.

The geographic delimitation of areas under certification assessment is another important practical topic. It is also an old issue: the original recommendation (e.g., by the late Antônio Carlos Silveira) was that they should be large units - countries or their primary divisions. The rationale was that a small area is likely to have neighbouring areas where vector control is not proceeding at the same pace and re-infestation may ensue through bug migration from nearby foci. This is a clear problem in the Gran Chaco, further complicated by peridomestic vectors that re-infest houses shortly after spraying (Cecere et al. 2013). While this "large-area rationale" worked well for the local elimination of introduced vector populations, it can be adapted to new scenarios. We proposed that the unit of assessment should match the administrative

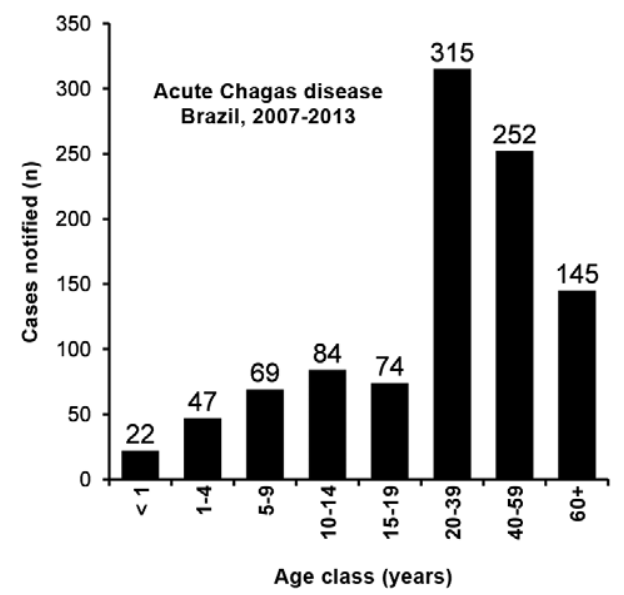

New confirmed cases of acute Chagas disease notified to the Brazilian Ministry of Health (years 2007-2013) stratified by age class. Data retrieved from dtr2004.saude.gov.br/sinanweb (September 5 2013). unit with political authority on budget decisions, which is in charge of vector control activities (Abad-Franch et al. 2013). Under a CGP strategy, it would not be critical whether the local vectors are native or non-native. Program activities would be actively monitored over time against a set of agreed process and endpoint indicators and this would obviously strengthen preventive action. Control-surveillance operational units should however operate within a clearly defined framework of supervision, co-ordination and technical support provided by more central levels (Abad-Franch et al. 2013).

Strict implementation of quality control measures is also necessary to improve disease and vector control programs. So far, rigorous internal and external quality control is only used for serodiagnosis, albeit not everywhere. CGPs could easily be designed to stimulate the definition and implementation of quality control measures for vector detection, insecticide spraying, epidemiological surveillance or any other crucial component of the program (Abad-Franch et al. 2013). This, again, means quality control over the processes, not just over outcome endpoints.

A related area that needs improvement is the transparency of the evaluations of Chagas disease status and control impact. To improve transparency, all the relevant primary data used in those evaluations should be made available for scrutiny. In addition, we believe that evaluation reports generated by expert committees should be peer-reviewed. These reports are much more influential to public health policy than most scientific papers, yet they skip the crucial step of being reviewed by anonymous experts. This should be done before any vital decision is made based on their conclusions and would open the possibility of multiple experts contributing to the evaluations with only a modest investment of time.

Finally, improvement of communication strategies is very much needed. "Interruption of transmission by species X in territory Z" has almost invariably been taken to mean "Chagas disease does not occur anymore in this territory" (Ramos Jr \& de Carvalho 2001). More elaborate, technically explicit and correct statements are important, but do not guarantee that the right message will get through. Message misreading was a key aspect of the grim post-CTI deactivation of most surveillance systems in Brazil (Ramos Jr \& de Carvalho 2001). This major drawback could be avoided by a carefully-designed CGP framework, with messages emphasising preparedness and long-term sustainable action in response to public health threats.

In our previous opinion paper, we highlighted some general problems with CITs and outlined an alternative strategy based on CGPs which could encourage sustained preventive action (Abad-Franch et al. 2013). Here we have shown how estimates of the key parameters used in Chagas disease control program assessment are all biased down. This bias may generate a false impression of fast progress towards target values and challenges the validity of CITs in currently widespread scenarios - particularly when native vector populations are involved in transmission and surveillance is weak. Such certificates 
have historically undermined some of the once-strongest control programs: the "punishment of success" is a real threat to disease prevention. Sustainable action will require dynamic assessment frameworks, rational program structures, strict quality control, more transparent evaluations and better communication strategies. Certification of good practice has the potential to improve all these crucial aspects and is therefore a promising alternative to CITs. Country officials, PAHO experts and the scientific community must join forces to develop improved strategic approaches that effectively benefit people living at risk of infection and prevent disease resurgence.

\section{REFERENCES}

Abad-Franch F, Diotaiuti L, Gurgel-Gonçalves R, Gürtler RE 2013. Certifying the interruption of Chagas disease transmission by native vectors: cui bono? Mem Inst Oswaldo Cruz 108: 251-254.

Abad-Franch F, Ferraz G 2010. "Didn't you see that bug...?" Investigating disease vector occurrence when detection is imperfect. Rev Soc Bras Med Trop 43 (Suppl. 2): S31-S34.

Abad-Franch F, Santos WS, Schofield CJ 2010. Research needs for Chagas disease prevention. Acta Trop 115: 44-54.

Abad-Franch F, Vega MC, Rolón MS, Santos WS, Rojas de Arias A 2011. Community participation in Chagas disease vector surveillance: systematic review. PLoS Negl Trop Dis 5: e1207.

Afonso AM, Ebell MH, Tarleton RL 2012. A systematic review of high quality diagnostic tests for Chagas disease. PLoS Negl Trop Dis 6: e1881.

Buitrago R, Waleckx E, Bosseno MF, Zoveda F, Vidaurre P, Salas R, Mamani E, Noireau F, Brenière SF 2010. First report of widespread wild populations of Triatoma infestans (Reduviidae, Triatominae) in the valleys of La Paz, Bolivia. Am J Trop Med Hyg 82: 574-579.

Cecere MC, Vázquez-Prokopec GM, Ceballos LA, Boragno S, Zárate JE, Kitron U, Gürtler RE 2013. Improved chemical control of Chagas disease vectors in the dry Chaco Region. J Med Entomol 50: 394-403

Chao A, Tsay PK, Lin SH, Shau WY, Chao DY 2001. The applications of capture-recapture models to epidemiological data. Stat Med 20: 3123-3157.

Conroy MJ, Runge JP, Barker RJ, Schofield MR, Fonnesbeck CJ 2008. Efficient estimation of abundance for patchily distributed populations via two-phase, adaptive sampling. Ecology 89: 3362-3370.

Gürtler RE 2009. Sustainability of vector control strategies in the Gran Chaco Region: current challenges and possible approaches. Mem Inst Oswaldo Cruz 104 (Suppl. I): 52-59.
Noireau F, Cortez MG, Monteiro FA, Jansen AM, Torrico F 2005. Can wild Triatoma infestans foci in Bolivia jeopardize Chagas disease control efforts? Trends Parasitol 21: 7-10.

Ostermayer AL, Passos ADC, Silveira AC, Ferreira AW, Macedo V, Prata AR 2011. O inquérito nacional de soroprevalência de avaliação do controle da doença de Chagas no Brasil (2001-2008). Rev Soc Bras Med Trop 44 (Suppl. 2): S108-S121.

PAHO - Pan-American Health Organization 2006. Estimación cuantitativa de la enfermedad de Chagas en las Américas. Document OPS/HDM/CD425-06, PAHO, Montevideo, 28 pp.

PAHO - Pan-American Health Organization 2011. XVIIIa Reunión de la Comisión Intergubernamental de la Iniciativa Subregional Cono Sur de Eliminación de Triatoma infestans y la Interrupción de la Transmisión Transfusional de la Tripanosomiasis Americana, Cochabamba, Bolivia, 2011 Julio 27-29, Document HSD/CD/00811, Organización Panamericana de la Salud, Montevideo, 69 pp.

Ramos Jr AN, de Carvalho DM 2001. Os diferentes significados da certificação conferida ao Brasil como estando livre da doença de Chagas. Cad Saude Publica 17: 1403-1412.

Rassi Jr A, Rassi A, Rojas de Arias A, Marin-Neto JA 2010. Chagas disease. Lancet 375: 1388-1402.

Rojas de Arias A, Abad-Franch F, Acosta N, López E, González N, Zerba E, Tarelli G, Masuh H 2012. Post-control surveillance of Triatoma infestans and Triatoma sordida with chemically-baited sticky traps. PLoS Negl Trop Dis 6: e1822.

Thompson WL 2004. Sampling rare or elusive species: concepts, designs and techniques for estimating population parameters, Island Press, Washington DC, 429 pp.

Walter SD, Irwig LM 1988. Estimation of test error rates, disease prevalence and relative risk from misclassified data: a review. J Clin Epidemiol 41: 923-937.

Yadón ZE, Gürtler RE, Tobar F, Medici AC 2006. Descentralización y gestión del control de enfermedades transmisibles en América Latina, UNICEF/UNDP/World Bank/WHO, Special Programme for Research \& Training in Topical Diseases (TDR), Organización Panamericana de la Salud, Buenos Aires, 320 pp.

Fernando Abad-Franch Instituto Leônidas e Maria Deane-Fiocruz, Manaus, AM, Brasil

Liléia Diotaiuti Centro de Pesquisas René Rachou-Fiocruz, Belo Horizonte, MG, Brasil

Rodrigo Gurgel-Gonçalves Universidade de Brasília, Brasília, DF, Brasil

Ricardo E Gürtler Universidad de Buenos Aires, Buenos Aires, Argentina 